\title{
Present but Absent in the Digital Age: Testing a Conceptual Model of Phubbing and Relationship Satisfaction among Married Couples
}

\author{
Shuaa Aljasir \\ King Abdulaziz University, Saudi Arabia \\ Correspondence should be addressed to Shuaa Aljasir; shaljasir@gmail.com
}

Received 8 October 2021; Revised 14 November 2021; Accepted 27 November 2021; Published 31 January 2022

Academic Editor: Zheng Yan

Copyright (c) 2022 Shuaa Aljasir. This is an open access article distributed under the Creative Commons Attribution License, which permits unrestricted use, distribution, and reproduction in any medium, provided the original work is properly cited.

\begin{abstract}
This study is the first to explain the determinant factors of phubbing-checking cell phone during a conversation or while spending time with a significant other-and its effect on the relationship satisfaction of both partners. It is also aimed at determining whether gender and relationship length play moderating roles in a relationship. The study adopted the media displacement theory and the interdependence theory to build a conceptual model of these variables. This cross-sectional research was conducted using an online survey with 741 voluntary married participants from Saudi Arabia. Upon analysis, the data confirmed that problematic usage of cell phone, Internet, social media, games, and SMS had a positive effect on phubbing. Interestingly, it showed that both the sample's and their partner's relationship satisfaction increased in line with phubbing behavior. Several theoretical and practical contributions have resulted from these findings.
\end{abstract}

\section{Introduction}

Considering the effects of cell phones on our lives and the amount of distraction they cause, it is imperative to increase research efforts on the influence of technology on human relationships. The number of people facing the ill effects of technology has been rising in recent years. According to a 2014 research report, $42 \%$ of unmarried participants in romantic relationships and $25 \%$ of partnered and married participants stated that their partners spent more time engaging with their mobile phones while they were with each other [1]. A 2015 survey reported that $90 \%$ of U.S. respondents had been on their phones while participating in the most recent social activity and $86 \%$ reported seeing others do the same [2].

"Phubbing" is the term used to describe a situation in which individuals spend time checking their cell phone during a conversation, which leads to neglect in interpersonal communication [3]. The word phubbing was created by merging two words, snubbing and phone, and describes excessive smartphone use [4]. Similarly, to be "phubbed" is to be neglected by another individual who is engaged with their cell phone [5]. When this situation occurs with a significant other or a spouse, it is called partner phubbing or Pphubbing.

Cell phones have become so ubiquitous that phubbing is nearly inevitable [6]. According to the findings of a study accomplished among college students by Karadağ et al. [7], the nature of smartphones makes phubbing unavoidable because they have the features of computers, with Internet access. This multidimensional structure leads to phubbing, which is a problematic issue. A literature review showed that no previous research has investigated whether some, none, or all of the dimensions that lead to phubbing among students and their colleagues would also apply to phubbing among married couples. Additionally, few studies have reviewed the causes of phubbing in terms of several digital problematic uses [7-9], and few studies have examined the effect of phubbing on relationship satisfaction [10-15]. These studies have investigated the phenomenon from the perspective of one partner and neglected the other.

Thus, the current literature is a little meagre regarding this relatively new phenomenon, and no study has investigated phubbing's possible predictors from the phubbing 
partner's perspective or the impacts of such behavior on the partner being phubbed. The use of such dyadic data offers a better understanding of dyadic practices that rule the functioning of these variables and the way the procedure could function mutually between couples. In addition, very few studies have investigated the moderating role of factors in this relationship $[13,15]$. Studying all these variables is essential in providing a complete picture of this multifaceted phenomenon, which is the aim of this research. In light of the foregoing perspectives, the current research intends to investigate a more integrative model to highlight the factors that influence phubbing and its impact on relationship satisfaction.

\section{Theoretical Background}

2.1. Phubbing: An Overview. According to the Macquarie Dictionary (the Australian national dictionary), phubbing became a societal practice in 2007 but was never discussed because no words existed to describe it (Macquarie [16]). In May 2012, McCANN Melbourne (the dictionary and the campaign advertising agency) invited phoneticians, cruciverbalists, lexicologists, poets, and authors to invent a word to define the act of ignoring others in a company. The word phubbing was coined in 2013 [17]. It is also used to describe the act of ignoring other people at social events by spending time on the phone surfing through Twitter, Snapchat, WhatsApp, or other chatting apps [4]. Phubbing can occur anywhere, during daily activities, lectures, meals, meetings, or social gatherings. As expected, phubbers often neglect their relationships by failing to communicate with those around them [18]. "Partner phubbing" is the term used to describe phubbing behavior in the occurrence of a romantic partner or spouse [13]. This behavior was first tested in a 2016 study by Roberts and David, wherein the phubbing scale was developed to examine how phubbing affects relationship satisfaction and romantic relationships in general. Answering the phone or text messages midconversation and scrolling through social media apps while in the presence of a partner are all examples of phubbing. Some research suggests that phubbing could be a problematic issue that is linked with a multidimensional structure. Karadağ et al. [7] argued that these dimensions include the problematic use of the Internet, games, phone, social media, and even short message service (SMS). According to Al-Saggaf and O'Donnell [19], the reviewed literature showed problematic technological usages such as problematic use of cell phone, SMS, and social media with phubbing behavior. Analyzing the interactions between these dynamics can help generate an exploratory model to analyze phubbing.

In particular, a study conducted by Roberts and David [13] had revealed that cell phone conflict was mediating the relationship between Pphubbing and relationship satisfaction. Chotpitayasunondh and Douglas [20] and Yam and Kumcağız [21] also demonstrated that phubbing behavior is predicted by cell phone problematic use. Ivanova et al. [22] had confirmed that a higher cell phone problematic use is associated with a higher phubbing behavior. Besides, Chatterjee [23] indicated that it is the main element that causes phubbing. Thus, this research is aimed at testing the following hypothesis:

$\mathrm{H}_{1}$ : problematic cell phone use has a positive impact on phubbing behavior.

Besides cell phone problematic use, a study conducted by Davey et al. [3] had shown that the most significant predictor correlated with phubbing behavior is problematic Internet use. Guazzini et al. [24] also indicated a robust association between such problematic use and phubbing. Benvenuti et al. [25] showed that a higher level of Internet problematic use increases the possibility of phubbing. Therefore, this study is aimed at testing the following hypothesis:

$\mathrm{H}_{2}$ : problematic Internet use has a positive impact on phubbing behavior.

However, Błachnio and Przepiorka [26] indicated that the social media platform Facebook is the main reason of phubbing behavior. Balta et al. [27] confirmed that a problematic use of the social media platform Instagram was greatly associated with phubbing behavior. A study by Chu et al. [28] confirmed that social media problematic use was correlated positively with peer phubbing. Thus, this research is aimed at testing the following hypothesis:

$\mathrm{H}_{3}$ : problematic social media use has a positive impact on phubbing behavior.

Besides social media problematic use, a study conducted by Verma et al. [29] had shown that problematic use of SMS and games was the main cause of phubbing. Therefore, this study is aimed at testing the following hypotheses:

$\mathrm{H}_{4}$ : problematic game use has a positive impact on phubbing behavior.

$\mathrm{H}_{5}$ : problematic SMS use has a positive impact on phubbing behavior.

\subsection{Media Displacement Theory, Relationship Satisfaction,} and Gender. In a romantic relationship, satisfaction entails a person's intrapersonal evaluation of their feelings about their relationship with their partner [30]. The literature on this topic suggests that to achieve relationship satisfaction, partners must satisfy each other's needs and desires [31]. Healthy interaction between spouses is also essential for relationship satisfaction [32]. In particular, the effects of phubbing on relationship satisfaction can be described using the media displacement theory, which proposes that people do not have unlimited time and attention, and participating in a different communication activity can prevent an individual from participating with other people [33]. In essence, communication time continues to decrease with the introduction of each new communication technology. Displacement theory can describe situations where parties have a narrow amount of time and attention to complete their daily routines [34]. The consequence of this reduced capacity is that it limits a person's ability to participate in other activities, which inadvertently leads the person to compromise on other activities [35]. The position of this theory is that spending time on devices like cell phones may reduce the number of meaningful interactions individuals can have with their spouse, which could reduce couples' relationship quality [36].

A 2014 study by Luo involving 395 participants revealed that texting has negative links with relationship satisfaction 
and positive links with attachment dimensions. Another study by Roberts and David [13] involving 145 adults posited that the impact of phubbing on relationships can be traced to disagreement about the usage of cell phones. They also discovered that the phubbing-smart phone-conflict relationship can be moderated by one's attachment style. They noticed a higher cell phone conflict level in people with anxious attachment styles and less conflict in people who are less attached to others. The research also revealed that phubbing has a direct impact on depression by way of relationship satisfaction and eventual life satisfaction. Furthermore, Wang et al.'s [14] study involving 243 married adults from China revealed that partner phubbing has certain negative effects on the level of relationship satisfaction which has its own negative impact on depression; partner phubbing has a positive effect on depression as a result of relationship dissatisfaction. However, a recent 2019 study by Wang et al. involving 429 adults from China revealed that no significant relationship exists between relationship satisfaction and partner phubbing; however, the association between relationship satisfaction and partner phubbing was moderated by selfesteem. Thus, the current study is also aimed at testing the following hypotheses:

$\mathrm{H}_{6}$ : phubbing behavior negatively affected relationship satisfaction:

$\mathrm{H}_{6 \mathrm{~A}}$ : phubbing behavior negatively affected participants' relationship satisfaction

$\mathrm{H}_{6 \mathrm{~B}}$ : phubbing behavior negatively affected participants' partners' relationship satisfaction

Although some studies have posited that men and women experience different levels of satisfaction in relationships [30,37-39], studies have revealed conflicting results regarding the role that gender would play as a moderator in the relationship between excessive use of cell phones and phubbing, whereas the study conducted by Karadağ et al. [7] revealed that gender played a role as a moderator in the relationship between excessive cell phone usage and phubbing. A research of Chotpitayasunondh and Douglas [20] and Ivanova et al. [22] showed no statistical significant role of the gender as a moderator in such a relationship. However, no known study has till date investigated the role of gender as a moderator in the relationship between phubbing and relationship satisfaction. Moreover, all these results are based on the perspective of one partner; none of them considered both partners about the impact of phubbing on their relationship satisfaction. Thus, this study is also aimed at testing the following hypothesis:

$\mathrm{H}_{7}$ : females moderated the relationship between phubbing behavior and relationship satisfaction more than males.

2.3. Interdependence Theory and Relationship Length. The interdependence theory places emphasis on the amount of influence individuals have over their partner's outcomes, which is why it is called the overarching relationship theory [40]. The theory details the impact and implications of the interdependence between people in relationships in terms of interaction, motivation, and cognition. The interdependence theory offers an avenue for analyzing these abstract and complex interpersonal situations. This theory also high- lights the importance of employing a dyadic perspective to better understand how the behavior of a spouse might affect the relationship. However, it has gradually evolved from a generic explanation of the different terms and conditions that affect interdependent relationships to an analysis of the contextual and dispositional factors affecting certain interdependence patterns [41]. The theory provides an essential framework to help us understand how social and personal relationships affect each partner's outcomes. Outcomes are a combination of costs and rewards-costs being the negative consequences (like conflict, antagonism, and anxiety) and rewards being the positive consequences (like gratification, pleasure, and happiness). Interdependence represents "the interpersonal reality" and "the foundation" through which certain motives are activated and the oriented cognition through which interaction unfolds [42].

The interdependence theory states that partners start to depend more on their relationship to meet their needs, as the relationship continues to develop, and that this dependence will eventually cause increased commitment and satisfaction [43]. Furthermore, relationship satisfaction comes from comparing the costs and rewards of the relationship with an internal standard. The decision to remain in a relationship, on the other hand, comes from comparing possible rewards and costs of the existing relationship with the costs and rewards of other available relationships. The theory posits that people in relationships are more likely to find satisfaction if its rewards are more than the costs [44]. The implication of this theory is that the relationship's rewards, such as intimate interactions and satisfying joint activities, would determine their level of satisfaction, to the extent that these rewards outweigh the costs, including pain, embarrassment, and distress. Thus, it could be speculated that individuals become attached and concerned about the welfare of their partners in the course of the relationship, which can motivate them to continue with the relationship even when they face dissatisfaction $[45,46]$. Hence, research also argues that relationship length has an essential role when it comes to relationship satisfaction [14, 47, 48]. However, other studies have indicated that because cell phone usage plays an important role in our everyday life, individuals may, on the contrary, consider their absence to cause dissatisfaction. For instance, a study by Ling and Donner [49] revealed that partners have even depended on these devices to sustain their romantic relationships. Duran et al. [50] also showed that about $40 \%$ of participants indicated that having rules regarding their cell phone usage was pointless when it came to their intimate relationships. Miller-Ott et al. [51] revealed that couples had been further contented in their relationships when they did not set restrictions that limited or controlled their cell phone usage.

This study intends to combine the hypotheses of this theory and the findings of the previous mentioned empirical research as a foundation to examine how relationship length affects the association between relationship satisfaction and phubbing among married adults. Thus, this research is aimed at investigating this final hypothesis:

$\mathrm{H}_{8}$ : the length of the relationship moderates the association between phubbing behavior and relationship satisfaction. 
Based on the literature review, the model which is demonstrated theoretically in Figure 1 was built to clarify aspects and their relations to phubbing.

\section{Methods}

3.1. Research Design and Participants. This cross-sectional study was done with 741 participants from Saudi Arabia who were married and aged 18 years or older. The survey was created and distributed online (for three months ending in January 2021) using Google Forms via various social media platforms. Informed consent was waived because the questionnaire was anonymous and voluntary. A Saudi sample was chosen as a convenience sample given that the researcher was Saudi. Seventy-nine incomplete surveys were excluded, leaving a total of 741 completed surveys. Among the total participants, 413 were males (55.7\%) and 328 were females $(44.3 \%)$. Their ages ranged between 18 and 78 years $(M=37.57, \mathrm{SD}=12.90)$.

3.2. Measures. Data were collected using several scales. The participant was requested to answer the 9-item Partner Phubbing Scale constructed by Roberts and David [13] (e.g., "During a typical mealtime that my partner and I spend together, my partner pulls out and checks the cell phone"; "My partner places the cell phone where they can see it when we are together"; and "My partner keeps the cell phone in their hand when they are with me"). Items were graded on a five-point Likert scale. They ranged from 1 (never) to 5 (all at time) (Cronbach's $\alpha=0.78$.

In addition to the Phubbing Scale, the participant was requested to also fill out the relationship satisfaction scale by Murray et al. [52]. This was a four-item scale (e.g., "I am extremely satisfied with my relationship"; "I have a very strong relationship with my partner"; and "My relationship with my partner is very rewarding"). Items were graded on a five-point Likert scale. They range from 1 (not at all) to 5 (completely true) (Cronbach's $\alpha=0.86$ ).

In addition, the participants were asked about their gender, their partners' genders, and the length of their relationship. The educational and economic levels, whether participants had jobs, their ages, and their partners' ages were also noted, to be treated as control variables. The levels of education ranged from 0 (uneducated) to 7 (graduate studies). Economic levels were measured on the scale from 1 (low class) to 3 (upper class). After completing these sections, participants were directed to ask their partner to complete the relationship satisfaction scale themselves as well as the last part of the questionnaire, which was aimed at understanding the reasons behind phubbing.

The partner was asked to complete the following scales by Karadağ et al. [8]: the mobile phone addiction scale (e.g., "I check over the screen of my mobile phone on all occasions". For this scale, the items were loaded onto 3 factors: deprivation (7 items, $\alpha=0.86$ ), control difficulties ( 3 items, $\alpha=0.78$ ), and application (5 items, $\alpha=0.85$ ).

The SMS addiction scale was a single-factor scale (e.g., "I check whether I have new incoming messages [SMS] or not on every occasion"; 6 items, $\alpha=0.80)$. The social media addiction scale (e.g., "I check over my social media [e.g., Twitter, Facebook] accounts even if I have something else to do") has 2 factors: sharing (6 items, $\alpha=0.82$ ) and control (4 items, $\alpha=0.79$ ). The Internet addiction scale (e.g., "I spend time using the internet more than I plan to") and the game addiction scale (e.g., "I have a need to replay a game aiming to win if I lost one") were also employed. Items of these scales were graded on a five-point Likert scale ranging from 1 (never) to 5 (always). This scale also had a single factor with 6 items $(\alpha=0.80)$.

3.3. Data Analysis. To analyze the relationship between excessive phone use and phubbing, six hierarchical regression analyses were carried out using SPSS to explore the predictive relationship of problematic behaviors such as excessive use of cell phones, Internet, social media, games, and SMS, given relationship satisfaction as the dependent variable. In addition, age, education, economic status, and employment status were included in each of the models as control variables. In all cases, for the first block of the analysis, the control variables, described above, were entered. In the second block, the predictor variables were entered.

To investigate the role of relationship length and gender as moderators, either in isolation or interaction, of the relationship between phubbing and participants' relationship satisfaction, a moderation analysis was conducted using the Hayes PROCESS extension of SPSS. This was organized in two separate analyses in which participants' and partners' relationship satisfactions were used as the dependent variables. In the first analysis of this hypothesis, the dependent variable was participants' relationship satisfaction, the predictor was phubbing, and the moderators were gender and relationship length. Further, age, education, economic status, and employment status were included in the model as control variables.

\section{Results}

4.1. Descriptive Statistics. Before the models were tested, the variables were inspected using descriptive statistics. The results show that the participant's relationship satisfaction deviated from the normal distribution in terms of kurtosis (3.158). All other variables fell within the acceptable range, except for minor deviations for a few variables. Reliability analysis also confirmed a high internal consistency for items measuring phubbing (0.87), relationship satisfaction (0.74), excessive use of cell phones (0.92), excessive Internet use (0.83), excessive use of social media (0.86), excessive use of game (0.92), and excessive SMS use (0.82). Tables 1 and 2 present the descriptive statistics regarding the participants' demographics and their responses to the scales.

Measures of internal validity were provided by Karadağ et al. [8] and Murray et al. [52]. In order to test that the same measures were in line with the original versions, Cronbach's $\alpha$ was calculated for each of the factors in the scales. The results demonstrated acceptable and good levels of internal validity (Table 3 ).

4.2. The Relationship between Cell Phone Excessive Use and Phubbing. For the first analysis, the predictor variable was 


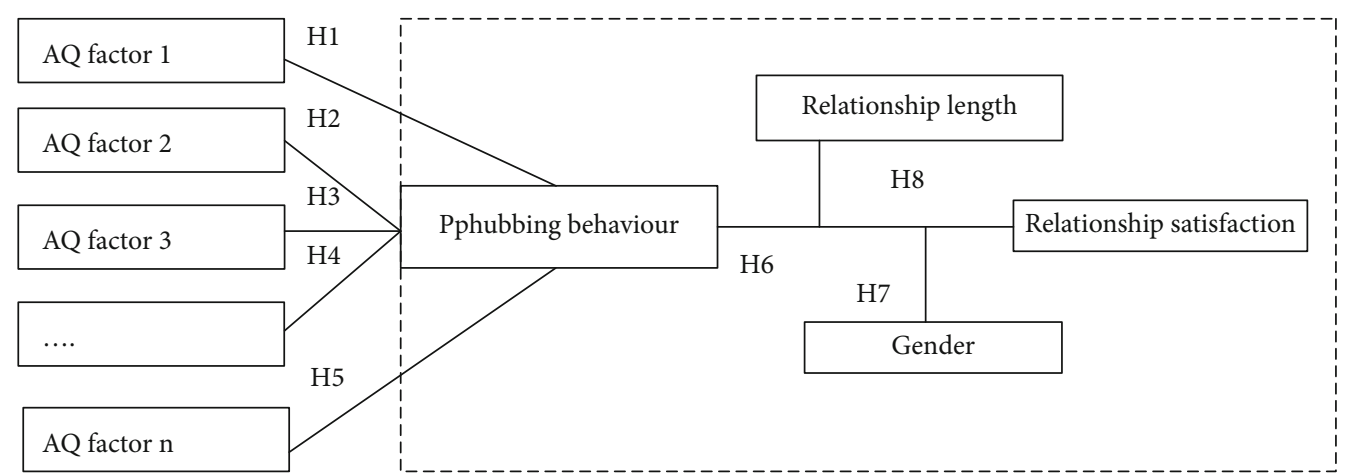

Figure 1: Conceptual moderation model of phubbing. The hypotheses are represented by $\mathrm{H}_{1}-\mathrm{H}_{8}$, where $\mathrm{H}_{1}-\mathrm{H}_{5}$ represent a hypothesized positive predictive relationship between the factors and phubbing behavior. $\mathrm{H}_{6}$ represents a hypothesized negative predictive relationship between phubbing behavior and relationship satisfaction. $\mathrm{H}_{7}$ and $\mathrm{H}_{8}$ relate to a predicted moderating effect of gender and relationship length on the relationship between phubbing behavior and relationship satisfaction. Relationship satisfaction would relate to either participant or partner dependent on the analysis performed. The dotted line represents the variables as represented by Hayes PROCESS model template two.

TABLE 1: Descriptive statistics of participant demographics.

\begin{tabular}{|c|c|c|c|c|c|}
\hline & $N$ & Minimum & Maximum & Mean & SD \\
\hline Age & 741 & 18.00 & 78.00 & 37.5655 & 12.90224 \\
\hline Gender & - & - & - & - & - \\
\hline Males & 413 & - & - & - & - \\
\hline Females & 328 & - & - & - & - \\
\hline Education level & 739 & 0.00 & 6.00 & 3.8512 & 1.54500 \\
\hline Economic status & 741 & 1.00 & 3.00 & 2.0405 & 0.66045 \\
\hline Relationship length & 737 & 1.00 & 48.00 & 9.7517 & 8.52534 \\
\hline Work status & - & - & - & - & - \\
\hline Working & 516 & - & - & - & - \\
\hline Not working & 225 & - & - & - & - \\
\hline
\end{tabular}

TABle 2: Descriptive statistics of participants' responses to scales.

\begin{tabular}{lccccccccc}
\hline & $N$ & Minimum & Maximum & Mean & SD & Skewness & SD & Kurtosis & SD \\
\hline Partner's relationship satisfaction & 739 & 1.00 & 5.00 & 3.8238 & 0.60303 & -0.040 & 0.090 & 0.628 & 0.180 \\
Participant's relationship satisfaction & 741 & 1.00 & 5.00 & 3.8468 & 0.64671 & -0.098 & 0.090 & 0.376 & 0.179 \\
Phubbing & 741 & 1.00 & 5.00 & 3.5674 & 0.82322 & -0.365 & 0.090 & -0.244 & 0.179 \\
Mobile addiction & 741 & 1.00 & 5.00 & 3.6113 & 0.78066 & -0.339 & 0.090 & -0.374 & 0.179 \\
Internet addiction & 741 & 1.00 & 5.00 & 3.5106 & 0.88128 & -0.332 & 0.090 & -0.550 & 0.179 \\
Social media addiction & 741 & 1.00 & 5.00 & 3.5555 & 0.77107 & -0.190 & 0.090 & -0.739 & 0.179 \\
Gaming addiction & 741 & 1.00 & 5.00 & 3.2881 & 1.04230 & -0.530 & 0.090 & -0.477 & 0.179 \\
SMS addiction & 741 & 1.00 & 5.00 & 3.3862 & 0.89141 & -0.135 & 0.090 & -0.713 & 0.179 \\
\hline
\end{tabular}

excessive cell phone use and the dependent variable was phubbing. In the first block of the analysis, the control variables were inserted while in the second block, the predictor variable was entered in addition to the control variables. Initially, standard residuals were analyzed and revealed that the data comprised no outliers (standard residual minimum $=-5.612$, standard residual maximum $=4.546)$. No violations of normality were observed. Standardized residuals' histogram and P-P plot showed almost normally distributed errors of data, which presented points that were near to the line (see Appendix I). The standardized scatterplot of predicted values revealed that the data satisfied the homogeneity of variance and linearity assumptions.

When looking at the amount of variance explained, the control variables accounted for $9.7 \%$ of variability $\left(R^{2}=\right.$ $0.097)$, whereas the model including the predictor variables accounted for $62.5 \% \quad\left(R^{2}=0.625 ; R^{2}\right.$ change $=0.528 ; \quad F$ change $=1030.866, p<0.001)$. The overall model, which 
TABLE 3: Measures of internal consistency for current participant responses.

\begin{tabular}{lc}
\hline Scale (factor) & Cronbach's $\alpha$ \\
\hline Phubbing & 0.87 \\
Respondent relationship satisfaction & 0.79 \\
Cell phone addiction & \\
$\quad$ Deprivation & 0.84 \\
Control difficulties & 0.63 \\
$\quad$ Application & 0.78 \\
SMS addiction & 0.82 \\
Social media & \\
$\quad$ Sharing & 0.79 \\
$\quad$ Control & 0.68 \\
Internet & 0.83 \\
Partner satisfaction & 0.74 \\
\hline
\end{tabular}

included the control variables and cell phone addiction, was a significant predictor of phubbing $(F(5,733)=244.178, p<$ $0.001, R^{2}=0.625, R^{2}$ adjusted $\left.=0.622\right)$. Participants' predicted phubbing score was $0.665+0.821$ (cell phone addiction score). Therefore, the phubbing score increased by 0.821 for each point of cell phone addiction.

For the second analysis, the predictor variable was excessive Internet use and the dependent variable was phubbing. For the first block of the analysis, the control variables were inputted while in the second block, the predictor variable was entered in addition to the control variables. Initially, standard residuals were analyzed and revealed that the data comprised no outliers (standard residual minimum $=-4.783$, std.residual maximum $=3.797$ ). No violations of normality were observed. Standardized residuals' histogram and P-P plot showed almost normally distributed errors of data, which presented points that were near to the line (see Appendix II). The standardized scatterplot of predicted values revealed that the data satisfied the homogeneity of variance and linearity assumptions.

When looking at the amount of variance explained, the control variables accounted for $9.7 \%$ of variability $\left(R^{2}=0.097\right)$, whereas the model including the predictor variables accounted for $53.3 \%\left(R^{2}=0.533 ; R^{2}\right.$ change $=0.435$; $F$ change $=682.971, p<0.001)$. The overall model, which included the control variables and Internet addiction, was a significant predictor of phubbing $(F(5,733)=167.103, p<$ $0.001, R^{2}=0.533, R^{2}$ adjusted $\left.=0.529\right)$. Participants' predicted phubbing score was $1.388+0.655$ (Internet addiction score). Therefore, the phubbing score increased by 0.655 for every point of the score of the Internet addiction.

For the third analysis, the predictor variable was social media excessive use and the dependent variable was phubbing. For the first block of the analysis, the control variables were inputted while in the second block, the predictor variable was entered in addition to the control variables. Initially, standard residuals were analyzed and revealed that the data comprised no outliers (standard residual minimum $=-4.185$, std.residual maximum $=3.719)$. No violations of normality were observed. Standardized residuals' histogram and P-P plot showed almost normally distributed errors of data, which presented points that were near to the line (see Appendix III). The standardized scatterplot of predicted values revealed that the data satisfied the homogeneity of variance and linearity assumptions.

When looking at the amount of variance explained, the control variables accounted for $9.7 \%$ of variability $\left(R^{2}=0.097\right)$, whereas the model including the predictor variables accounted for $50.8 \%\left(R^{2}=0.508 ; R^{2}\right.$ change $=$ $0.411 ; F$ change $=613.240, p<0.001)$. The overall model, which included the control variables and social media excessive use, was a significant predictor of phubbing $\left(F(5,733)=151.655, \quad p<0.001, \quad R^{2}=0.508, \quad R^{2}\right.$ adjusted $=$ 0.505). Participants' predicted phubbing score was 1.119 +0.727 (social media addiction score). Therefore, the phubbing score increased by 0.727 for each social media addiction score.

For the fourth analysis, the predictor variable was excessive gaming use and the dependent variable was phubbing. For the first block of the analysis, the control variables were inputted while in the second block, the predictor variable was entered in addition to the control variables. Initially, standard residuals were analyzed and revealed that the data comprised no outliers (standard residual minimum $=-3.412$, std. residual maximum $=4.662$ ). No violations of normality were observed. Standardized residuals' histogram and P-P plot showed almost normally distributed errors of data, which presented points that were near to the line (see Appendix IV). The standardized scatterplot of predicted values revealed that the data satisfied the homogeneity of variance and linearity assumptions.

When looking at the amount of variance explained, the control variables accounted for $9.7 \%$ of variability $\left(R^{2}=0.097\right)$, whereas the model including the predictor variables accounted for $48.3 \%\left(R^{2}=0.483 ; R^{2}\right.$ change $=0.386 ; F$ change $=546.537, p<0.001)$. The overall model, which included the control variables and gaming addiction, was a significant predictor of phubbing $(F(5,733)=136.877, p<$ $0.001, R^{2}=0.483, R^{2}$ adjusted $\left.=0.479\right)$. Participants' predicted phubbing score was $3.078+0.512$ (gaming addiction score). Therefore, the phubbing score increased by 0.512 points for each gaming addiction score.

For the final analysis, the predictor variable was excessive SMS use and the dependent variable was phubbing. For the first block of the analysis, the control variables were entered while in the second block, the predictor variable was inputted in addition to the control variables. Initially, standard residuals were analyzed and revealed that the data comprised no outliers (standard residual minimum $=-3.790$, std.residual maximum $=3.812$ ). No violations of normality were observed. Standardized residuals' histogram and P-P plot showed almost normally distributed errors of data, which presented points that were near to the line (see Appendix V). The standardized scatterplot of predicted values revealed that the data satisfied the homogeneity of variance and linearity assumptions.

When looking at the amount of variance explained, the control variables accounted for $9.7 \%$ of variability 
$\left(R^{2}=0.097\right)$, whereas the model including the predictor variables accounted for $46.1 \%\left(R^{2}=0.461 ; R^{2}\right.$ change $=0.363$ ; $F$ change $=493.609, p<0.001)$. The overall model, which included the control variables and SMS addiction, was a significant predictor of phubbing $(F(5,733)=125.151, p<0.001$, $R^{2}=0.461, \quad R^{2}$ adjusted $\left.=0.457\right)$. Participants' predicted phubbing score was $1.847+0.589$ (SMS addiction score). Therefore, the phubbing score increased by 0.589 for each point of the SMS addiction score.

\subsection{The Relationship between Phubbing and Relationship Satisfaction, with the Moderation Role of Gender and the Length of Relationship}

4.3.1. Participant Relationship Satisfaction. Standard residuals were analyzed and revealed that the data had no outliers (standard residual minimum $=-4.580, \quad$ standard residual maximum $=3.038$ ). Assessments to verify if the data confirmed the collinearity's assumption showed that multicollinearity was not a matter (phubbing, tolerance $=$ 0.682 , VIF $=1.161$; relationship length, tolerance $=0.576$, $\mathrm{VIF}=1.737$; and gender, tolerance $=0.779, \mathrm{VIF}=1.284$ ) The data confirmed the independent errors' assumption (Durbin-Watson value $=1.525$ ). The standardized residuals' histogram and the normal P-P plot showed that the data had almost normally distributed errors. The standardized predicted values' scatterplot revealed that the data satisfied the homogeneity of variance and linearity assumptions (see Appendix VI).

Initially, the association between phubbing and participant relationship satisfaction was explored. A significant regression equation was found $(F(9,725)=23.723, p<$ 0.001 ), with an $R^{2}$ of 0.228 . Within this model, participants' predicted satisfaction was $3.404+0.1780$ (phubbing score). Therefore, participants' relationship satisfaction increased by 0.1780 for each point of the phubbing score.

For the moderation analysis, Hayes PROCESS model number two was used (Figure 1). In this analysis, the dependent variable was participant relationship satisfaction. The results of the analysis demonstrated that the interaction between phubbing and gender was not significant $(b=-0.0334$, C.I. $(-0.12,0.07), p=0.531)$. Furthermore, the interaction between phubbing and relationship length was not significant $(b=-0.0012$, C.I. $(-0.01,0.01), p=$ $0.697)$. For conditional effects, the 16 th, 50 th, and 84 th percentiles were used for low, medium, and high values, respectively. In terms of condition effects, for males, at a low moderation relationship length of -7.740 , the conditional effect was 0.1875 (C.I. $(0.10,0.28), p<0.001)$; at a medium relationship length of -2.740 , the conditional effect was 0.1814 (C.I $(0.11,0.25), p<0.001)$; and at a high relationship length of 10.260 , the conditional effect was 0.1655 (C.I (0.08, $0.25), p<0.001)$. For females, at a low relationship length of -7.740 , the conditional effect was 0.1541 (C.I. $(0.07,0.24), p$ $<0.001)$; at a medium relationship length of -2.740 , the conditional effect was 0.1480 (C.I. $(0.06,0.23), p<0.001)$; and at a high relationship length of 10.260 , the conditional effect was 0.1321 (C.I. $(0.02,0.24), p<0.05$; see Figure 2).
4.3.2. Partner Relationship Satisfaction. In the second analysis of this hypothesis, the dependent variable was partner relationship satisfaction, the predictor was phubbing, and the moderators were gender and relationship length. Furthermore, age, education, economic status, and employment status were included in the model as control variables.

Standard residuals were analyzed and revealed that the data comprised no outliers (standard residual minimum $=$ -3.971 , standard residual maximum $=2.739$ ). Assessments to verify if the data confirmed the collinearity's assumption showed that multicollinearity was not a matter (phubbing, tolerance $=0.863$, VIF $=1.158$; relationship length, tolerance $=0.576, \quad \mathrm{VIF}=1.737$; and gender, tolerance $=$ $0.776, \mathrm{VIF}=1.289$ ). The data confirmed the independent errors' assumption (Durbin-Watson value $=1.545$ ). The standardized residuals' histogram and the normal P-P plot showed that the data had almost normally distributed errors. The standardized predicted values' scatterplot satisfied the homogeneity of variance and linearity assumptions (see Appendix VII).

Initially, the relationship between phubbing and partner relationship satisfaction was explored. A significant regression equation was found $(F(9,723)=18.179, p<0.001)$, with an $R^{2}$ of 0.185 . Within this model, participants' predicted satisfaction was $3.4717+0.1531$ (phubbing score). Therefore, partner relationship satisfaction increased by 0.1531 for each point of the phubbing score.

For the moderation analysis, Hayes PROCESS model number two was used (Figure 1). In this analysis, the dependent variable was partner relationship satisfaction. The results of the analysis demonstrated that the moderation of the relationship between phubbing and partner relationship satisfaction and phubbing and gender interaction was not significant $(b=-0.0296$, C.I. [-0.13, 0.07], $p=0.562)$. Further, the interaction between phubbing and relationship length was not significant $(b=-0.0011$, C.I. $(-0.01,0.01)$, $p=0.714)$. As with the previous analysis, the 16th, 50th, and 84th percentiles were used to test conditional effects at low, medium, and high values, respectively. For males, at a low moderation relationship length of -7.752 , the conditional effect was 0.1616 (C.I. $(0.08,0.25), p<0.001)$; at a medium relationship length of -2.752 , the conditional effect was 0.1561 (C.I. $(0.87,0.23), p<0.001$ ); and at a high relationship length of 10.248 , the conditional effect was 0.1417 (C.I. $(0.06,0.23), p<0.001)$. For females, at a low relationship length at -7.752 , the conditional effect was 0.1320 (C.I. $(0.05,0.22), p<0.01)$; at a medium relationship length of -2.752 , the conditional effect was 0.1265 (C.I. (0.05, $0.20), p<0.01)$; and at a high relationship length of 10.248 , the conditional effect was 0.1121 (C.I. $(0.01,0.22), p<0.05$; see Figure 3).

\section{Discussion}

This study is aimed at bridging the gap in knowledge regarding the phenomenon of phubbing by determining the factors of phubbing behavior and its impact on the relationship satisfaction of both partners. In addition, it is aimed at determining whether gender and relationship 


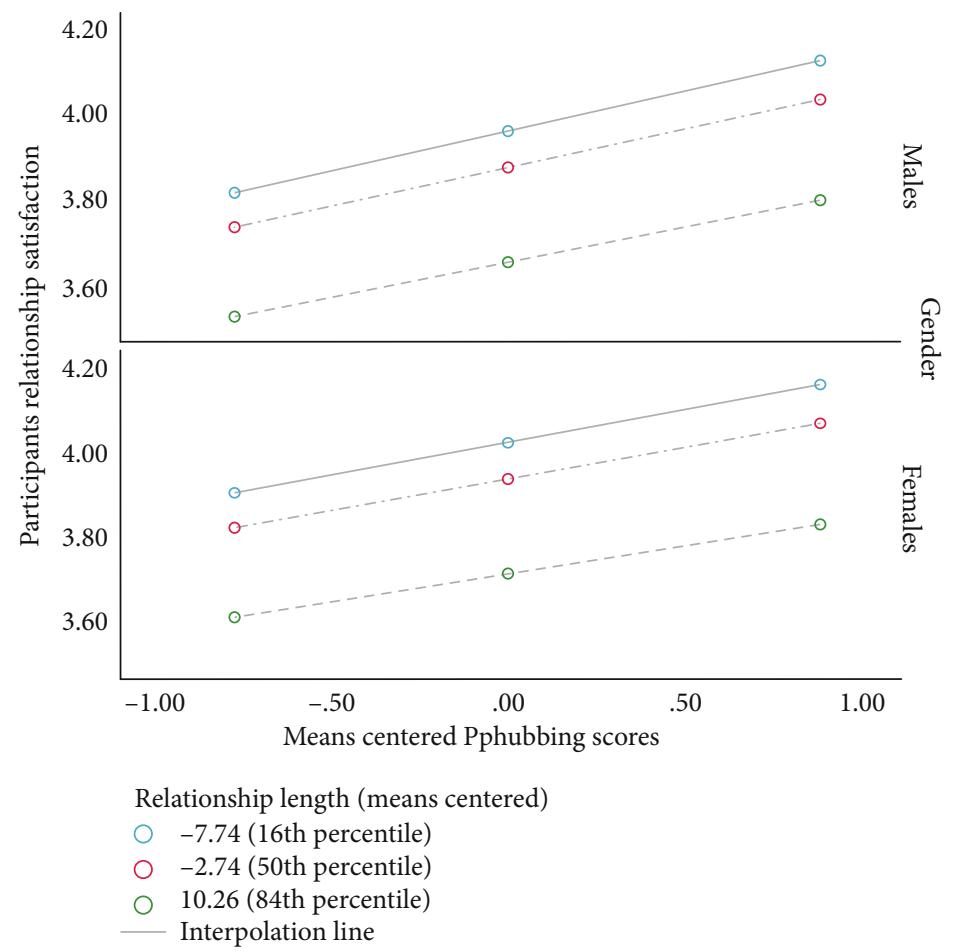

FIgUre 2: Paneled tumble plot of conditional effects of participants' relationship length. Paneled tumble plot of conditional effects of participants' relationship length at low, medium, and high values of mean-centered scores represented by $16^{\text {th }}$ (blue), $50^{\text {th }}$ (red), and $84^{\text {th }}$ (green) percentiles, respectively. For each value of relationship length, the estimated marginal mean of nonstandardized participant relationship scores was plotted for mean-centered phubbing scores at the $16^{\text {th }}, 50^{\text {th }}$, and $84^{\text {th }}$ percentiles.

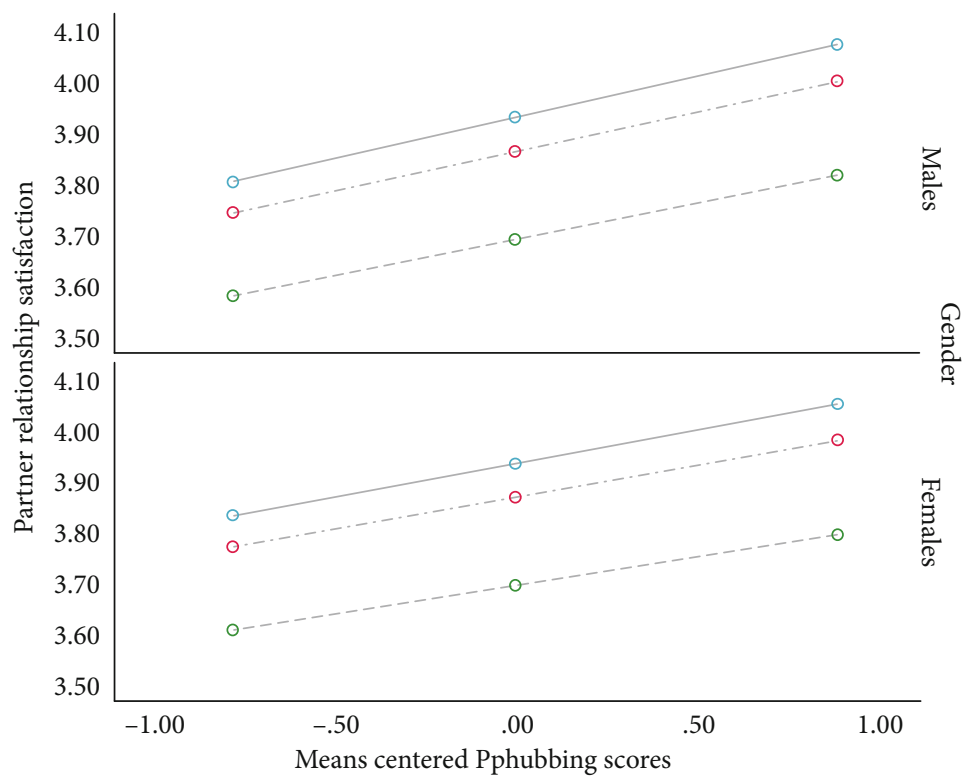

Relationship length (means centered)

○ -7.75 (16th percentile)

○ -2.75 (50th percentile)

○ 10.25 (84th percentile)

Interpolation line

FIGURE 3: Paneled tumble plot of conditional effects of partner relationship length. Paneled tumble plot of conditional effects of partner relationship length at low, medium, and high values of mean-centered scores represented by $16^{\text {th }}$ (blue), $50^{\text {th }}$ (red), and $84^{\text {th }}$ (green) percentiles, respectively. For each value of relationship length, the estimated marginal mean of nonstandardized partner relationship scores was plotted for mean-centered phubbing scores at the $16^{\text {th }}, 50^{\text {th }}$, and $84^{\text {th }}$ percentiles. 
length play moderating roles. Upon analysis, the data collected for this purpose showed interesting results. While previous research indicated that phubbing is a phenomenon that could be considered a problematic issue with a multidimensional structure [7], the current research reveals different findings. The results confirmed that problematic use of cell phone, Internet, social media, games, and SMS had a positive effect on phubbing $\left(\mathrm{H}_{1}\right.$ to $\left.\mathrm{H}_{5}\right)$, meaning that excessive use was the reason behind phubbing. These results confirm that phubbing is a problematic issue with a multidimensional structure. The results are in line with the results of previous studies that reveal that excessive usage of certain dimensions of cell phones would increase phubbing behavior [7, 8, 21].

However, the study reveals interesting results regarding the influence of phubbing behavior on relationship satisfaction $\left(\mathrm{H}_{6}\right)$. This hypothesis was not supported; in fact, the reverse was true. It appears that both participant and partner relationship satisfaction increased in line with phubbing behavior. These results contradict the findings of some previous studies that revealed that the relationship satisfaction of the person being phubbed correlates negatively with phubbing [53-55]. The results also contradict the hypothesis of the media displacement theory that posits that spending too much time on cell phones could reduce or displace meaningful interactions among couples, which eventually leads to undermining relationship satisfaction [13].

Thus, the current study contributes to the literature by indicating that both those who phubbed their partners and those who are being phubbed do not feel dissatisfied in their relationships. It could be argued that as cell phones start to occupy a dominant part in our daily life, using them becomes essential and not a luxury. Ling and Donner (2009) confirmed that because cell phone usage plays an important role in everyday life, individuals may, on the contrary, realize that their absence would cause negative feeling. Partners have even become reliant on these devices to sustain their romantic relationships. The findings of the current study are also in line with the results of Duran et al. [50] who disclosed that about $40 \%$ of participants indicated that having rules regarding their cell phone usage was pointless when it came to their romantic relationships. These results also matched the findings of Miller-Ott et al. [51] who revealed that their sample was more relationally satisfied when they did not set rules that limited or controlled their cell phone usage. Thus, it could be argued that the participants perceived that they did not engage in phubbing behavior to run away from their reality or dissatisfaction with the real world but considered such usage as an essential pillar in their daily life. These findings clearly illustrate that phubbing could not be viewed as a problematic behavior, as was believed before.

Although this research extends the existing literature by testing the relationship satisfaction level from the perspective of the phubbing partner for the first time, this area clearly needs further exploration. It should be noted that this study is the first to explore the influence of phubbing on the relationship satisfaction of both partners. Due to the lack of studies that focus on this area, such interesting findings should be further investigated by focusing on both partners, to reach a full understanding of such behavior.

A review of the studies examining the moderating role of gender in the relationship with phubbing revealed conflicting results. The study conducted by Karadağ et al. [7] revealed the moderation role of gender in the relationship between excessive cell phone usage and phubbing. Research done by Chotpitayasunondh and Douglas [20] and Ivanova et al. [22] showed that gender had no moderation role in such a relationship. The results of the current study also revealed that gender did not moderate the relationship between phubbing and relationship satisfaction $\left(\mathrm{H}_{7}\right)$. Thus, the results of this study contradict those of previous studies that indicate that men and women experience different levels of satisfaction in relationships [30, 37-39]. It appears that when it comes to the relationship between phubbing and relationship satisfaction, gender does not play a moderating role.

Finally, the results of this study showed that the length of the relationship did not moderate the relationship between phubbing behavior and relationship satisfaction $\left(\mathrm{H}_{8}\right)$. Interestingly, such findings contradict what has been revealed in the previous research regarding the positive correlation between the relationship length and the level of satisfaction $[14,47,48]$. According to the interdependence theory [40, 43], a person is more motivated to maintain and develop a relationship when the benefit outweighs the cost, while poor alternatives could also affect their relationship satisfaction level. Thus, it could be argued that being satisfied in a romantic relationship determines such an evaluation, which could have been determined since the beginning of the relationship and thus is not affected by its length.

\section{Limitations, Implications, and Future Studies}

While this research adds to the literature on phubbing in several ways, some essential limitations should be highlighted. First, the current study was cross-sectional research. Accordingly, readers should be careful about the causal implications. Second, qualitative research via a follow-up interview could be conducted to provide further details about phubbing that might be difficult to obtain during the quantitative study. Since the study's respondents came from the Middle East region, the results are especially valid for collective societies that foster strong family relationships where everyone takes responsibility for each other. Thus, in order to understand phubbing globally, further studies could be accomplished among diverse cultural contexts to demonstrate how the factors studied in this research influence phubbing behavior among married couples. Besides, further investigation would explore the effect of both partners' phubbing in comparison to one.

Notwithstanding its limitations, this study makes several theoretical and practical contributions. From a theoretical perspective, the determinants of phubbing among married couples have been identified. Second, the study tested a conceptual model of relationships between Internet addiction, game addiction, phone addiction, social media addiction, SMS addiction, phubbing, gender, relationship length, and 
relationship satisfaction. This model showed a distinctive perspective that has not been clarified in current literature. The relationships discovered when examining the model would highlight on the new social phenomenon of phubbing and might encourage scholars leading research on married couples to study these variables. Third, this is the first study that includes dyadic data while investigating phubbing. Therefore, it measures the true interdependence between partners, as it incorporates data from both partners. This usage of such dyadic data offers a better understanding of practices that could rule the function of these variables and how the procedure could function mutually between couples in the dyad.

From a practical perspective, the intent of this study was to improve the understanding of phubbing, which is still new and therefore has not been comprehensively examined. In general, this research offers a model of phubbing. Having a clear set of variables associated with phubbing could be beneficial for digital media platform developers and provide them with insights. Furthermore, the findings of this study help determine the need for social practitioners working with couples undergoing relationship issues to include an understanding of digital media technologies, in particular cell phone usage, into their practice to increase their understanding of how these digital tools affect married couples' relationship satisfaction.

\section{Data Availability}

The results of this manuscript are based on data collected from an online survey available through Google Forms. The following is the URL link to the survey: https://docs.google.com/ forms/d/e/1FAIpQLScg2474Ze2QT0t8gTZxQiKwi6c7DbRee KB_nraOFHetkTAdBzw/viewform?usp=sf_link.

\section{Conflicts of Interest}

The author declares that he has no conflicts of interest.

\section{Supplementary Materials}

Appendices I, II, III, IV, V, VI, and VII. (Supplementary Materials)

\section{References}

[1] A. Lenhart and M. Duggan, Couples, the Internet, and social media, Internet and Technology, 2014.

[2] A. Lenhart, M. Anderson, and A. Smith, Teens, technology and romantic relationships, Internet and Technology, 2015.

[3] S. Davey, A. Davey, S. K. Raghav et al., "Predictors and consequences of "phubbing" among adolescents and youth in India: an impact evaluation study," Journal of Family \& Community Medicine, vol. 25, no. 1, pp. 35-42, 2018.

[4] W. S. Pendergrass and C. Town, "Phubbing: communication in the attention economy," in Paper presented at the Conference on Information Systems Applied Research, Austin, Texas, USA, 2017.

[5] V. Chotpitayasunondh and K. M. Douglas, "Measuring phone snubbing behavior: development and validation of the generic scale of phubbing (GSP) and the generic scale of being phubbed (GSBP)," Computers in Human Behavior, vol. 88, pp. 5-17, 2018.

[6] O. Grace, "The impact of pphubbing and age on present/ absence and well-being within romantic relationships," Dublin Business School, 2018, (Unpublished bachelor's thesis).

[7] E. Karadağ, Ş. B. Tosuntaş, E. Erzen et al., "Determinants of phubbing, which is the sum of many virtual addictions: a structural equation model," Journal of Behavioral Addictions $J B A$, vol. 4, no. 2, pp. 60-74, 2015.

[8] E. Karadağ, Ş. B. Tosuntaş, E. Erzen et al., "The Virtual World's Current Addiction: Phubbing," The Turkish Journal on Addiction, vol. 3, no. 2, pp. 223-269, 2016.

[9] M. A. Rahman, M. Duradoni, and A. Guazzini, "Identification and prediction of phubbing behavior: a data-driven approach," Neural Computing and Applications, pp. 1-10, 2021.

[10] R. Cummings, Channel Association in Face-to-Face Interactions: The Effects of Smartphone Use on Conversational Satisfaction, Purdue University, 2017, (Unpublished doctoral dissertation).

[11] D. Halpern and J. E. Katz, "Texting's consequences for romantic relationships: a cross-lagged analysis highlights its risks," Computers in Human Behavior, vol. 71, pp. 386-394, 2017.

[12] E. K. Oliveira, The Relationship between Mobile Device Usage and Couple Satisfaction (Unpublished Doctoral Dissertation), University of Missouri, 2016.

[13] J. A. Roberts and M. E. David, "My life has become a major distraction from my cell phone: partner phubbing and relationship satisfaction among romantic partners," Computers in Human Behavior, vol. 54, pp. 134-141, 2016.

[14] X. Wang, X. Xie, Y. Wang, P. Wang, and L. Lei, "Partner phubbing and depression among married Chinese adults: the roles of relationship satisfaction and relationship length," Personality and Individual Differences, vol. 110, pp. 12-17, 2017.

[15] X. Wang, F. Zhao, and L. Lei, "Partner phubbing and relationship satisfaction: self-esteem and marital status as moderators," Current Psychology, vol. 40, no. 7, pp. 3365-3375, 2021.

[16] M. Dictionary, “Ever been phubbed?," 2016, https://www .macquariedictionary.com.au/blog/article/391/.

[17] P. Chasombat, "Facebook effects on interpersonal communication: study on Thai young adult," Journal of Public and Private Management, vol. 22, no. 1, pp. 45-70, 2015.

[18] N. G. Ugur and T. Koc, "Time for digital detox: misuse of mobile technology and phubbing," Procedia-Social and Behavioral Sciences, vol. 195, pp. 1022-1031, 2015.

[19] Y. Al-Saggaf and S. B. O'Donnell, "Phubbing: perceptions, reasons behind, predictors, and impacts," Human Behavior and Emerging Technologies, vol. 1, no. 2, pp. 132-140, 2019.

[20] V. Chotpitayasunondh and K. M. Douglas, "How "phubbing" becomes the norm: The antecedents and consequences of snubbing via smartphone," Computers in Human Behavior, vol. 63, pp. 9-18, 2016.

[21] F. C. Yam and H. Kumcağız, "Adaptation of general phubbing scale to Turkish culture and investigation of phubbing levels of university students in terms of various variables," Addicta: The Turkish Journal on Addictions, vol. 7, no. 1, pp. 48-60, 2020.

[22] A. Ivanova, O. Gorbaniuk, A. Błachnio et al., "Mobile phone addiction, phubbing, and depression among men and women: a moderated mediation analysis," Psychiatric Quarterly, vol. 91, no. 3, pp. 655-668, 2020. 
[23] S. Chatterjee, "Antecedents of phubbing: from technological and psychological perspectives," Journal of Systems and Information Technology, vol. 22, no. 2, pp. 161-178, 2020.

[24] A. Guazzini, M. Duradoni, A. Capelli, and P. Meringolo, "An explorative model to assess individuals' phubbing risk," Future Internet, vol. 11, no. 1, p. 21, 2019.

[25] M. Benvenuti, A. Błachnio, A. M. Przepiorka, V. M. Daskalova, and E. Mazzoni, "Factors related to phone snubbing behavior in emerging adults: the phubbing phenomenon," in The Psychology and Dynamics behind Social Media Interactions, pp. 164-187, IGI Global, 2020.

[26] A. Błachnio and A. Przepiorka, "Be aware! If you start using Facebook problematically you will feel lonely: phubbing, loneliness, self-esteem, and Facebook intrusion. A cross-sectional study," Social Science Computer Review, vol. 37, no. 2, pp. 270-278, 2019.

[27] S. Balta, E. Emirtekin, K. Kircaburun, and M. D. Griffiths, "Neuroticism, trait fear of missing out, and phubbing: the mediating role of state fear of missing out and problematic Instagram use," International Journal of Mental Health and Addiction, vol. 18, no. 3, pp. 628-639, 2020.

[28] X. Chu, S. Ji, X. Wang, J. Yu, Y. Chen, and L. Lei, "Peer phubbing and social networking site addiction: the mediating role of social anxiety and the moderating role of family financial difficulty," Frontiers in Psychology, vol. 12, article 670065, 2021.

[29] S. Verma, R. Kumar, and S. K. Yadav, "The determinants of phubbing behaviour: a millenials perspective," International Journal of Innovative Technology and Exploring Engineering (IJITEE), vol. 8, no. 125, pp. 806-812, 2019.

[30] N. Sakalli-Ugurlu, "How do romantic relationship satisfaction, gender stereotypes, and gender relate to future time orientation in romantic relationships?," The Journal of Psychology, vol. 137, no. 3, pp. 294-303, 2003.

[31] B. W. Hadden, C. V. Smith, and C. R. Knee, "The way I make you feel: how relatedness and compassionate goals promote partner's relationship satisfaction," The Journal of Positive Psychology, vol. 9, no. 2, pp. 155-162, 2014.

[32] B. S. Meeks, S. S. Hendrick, and C. Hendrick, "Communication, love and relationship satisfaction," Journal of Social and Personal Relationships, vol. 15, no. 6, pp. 755-773, 1998.

[33] A. C. B. Angeluci and G. Huang, "Rethinking media displacement: the tensions between mobile media and face-to-face interaction," Revista FAMECOS: mídia, cultura e tecnologia, vol. 22, no. 4, pp. 173-190, 2015.

[34] S. C. J. Sin and P. Vakkari, "Information repertoires: media use patterns in various gratification contexts," Journal of Documentation, vol. 73, no. 6, pp. 1102-1118, 2017.

[35] J. Newell, J. J. Pilotta, and J. C. Thomas, "Mass media displacement and saturation," International Journal on Media Management, vol. 10, no. 4, pp. 131-138, 2008.

[36] A. K. Przybylski and N. Weinstein, "Can you connect with me now? How the presence of mobile communication technology influences face-to-face conversation quality," Journal of Social and Personal Relationships, vol. 30, no. 3, pp. 237246, 2013.

[37] E. E. Fallis, U. S. Rehman, E. Z. Woody, and C. Purdon, “The longitudinal association of relationship satisfaction and sexual satisfaction in long-term relationships," Journal of Family Psychology, vol. 30, no. 7, pp. 822-831, 2016.
[38] J. D. Ragsdale, "Gender, satisfaction level, and the use of relational maintenance strategies in marriage," Communication Monographs, vol. 63, no. 4, pp. 354-369, 1996.

[39] C. A. Surra and M. Longstreth, "Similarity of outcomes, interdependence, and conflict in dating relationships," Journal of Personality and Social Psychology, vol. 59, no. 3, pp. 501-516, 1990.

[40] H. H. Kelley and J. W. Thibaut, Interpersonal Relations: A Theory of Interdependence, Wiley, 1978.

[41] H. Kelley and J. Holmes, Interdependence Theory: Situations, Relationships, and Personality [Unpublished Manuscript], University of California, 2003.

[42] C. E. Rusbult, M. Kumashiro, M. K. Coolsen, and J. L. Kirchner, "Interdependence, closeness, and relationships," in Handbook of Closeness and Intimacy, D. J. Mashek and A. P. Aron, Eds., pp. 137-161, Lawrence Erlbaum Associates Publishers, 2004.

[43] J. Thibaut and H. Kelley, The Social Psychology of Groups, Wiley, 1959.

[44] C. E. Rusbult and P. A. M. Van Lange, "Interdependence, interaction, and relationships," Annual Review of Psychology, vol. 54, no. 1, pp. 351-375, 2003.

[45] C. E. Rusbult and B. P. Buunk, "Commitment processes in close relationships: an interdependence analysis," Journal of Social and Personal Relationships, vol. 10, no. 2, pp. 175-204, 1993.

[46] C. E. Rusbult, J. Verette, G. A. Whitney, L. F. Slovik, and et al, "Accommodation processes in close relationships: theory and preliminary empirical evidence," Journal of Personality and social Psychology, vol. 60, no. 1, pp. 53-78, 1991.

[47] J. K. Monk, A. V. Vennum, B. G. Ogolsky, and F. D. Fincham, "Commitment and sacrifice in emerging adult romantic relationships," Marriage \& Family Review, vol. 50, no. 5, pp. 416-434, 2014.

[48] S. W. Whitton and A. D. Kuryluk, "Relationship satisfaction and depressive symptoms in emerging adults: cross-sectional associations and moderating effects of relationship characteristics," Journal of Family Psychology, vol. 26, no. 2, pp. 226-235, 2012.

[49] R. Ling and J. Donner, Mobile communication, Polity Press, Malden, MA, 2009.

[50] R. L. Duran, L. Kelly, and T. Rotaru, "Mobile phones in romantic relationships and the dialectic of autonomy Versus connection," Communication Quarterly, vol. 59, no. 1, pp. 19-36, 2011.

[51] A. E. Miller-Ott, L. Kelly, and R. L. Duran, "The effects of cell phone usage rules on satisfaction in romantic relationships," Communication Quarterly, vol. 60, no. 1, pp. 17-34, 2012.

[52] S. L. Murray, J. G. Holmes, D. W. Griffin, and J. L. Derrick, "The equilibrium model of relationship maintenance," Journal of Personality and Social Psychology, vol. 108, no. 1, pp. 93113, 2015.

[53] R. A. Elphinston and P. Noller, "Time to face it! Facebook intrusion and the implications for romantic jealousy and relationship satisfaction," Cyberpsychology, Behavior and Social Networking, vol. 14, no. 11, pp. 631-635, 2011.

[54] A. Miller-Ott and L. Kelly, "The presence of cell phones in romantic partner face-to-face interactions: an expectancy violation theory approach," Southern Communication Journal, vol. 80, no. 4, pp. 253-270, 2015.

[55] D. J. Roache, "Can You Just Put Your Phone Away?": The Effects of Cell Phone Use on Face-to-Face Conflict in Romantic Relationships, University of Illinois, 2018, (Unpublished doctoral dissertation). 